\title{
Imperativo categórico y republicanismo kantiano desde la sociedad civil
}

\author{
Kant's categorical imperative and republicanism from \\ the perspective of civil society
}

DOI: 10.33539/consensus.2019.v24n1.2239

Alessandro Caviglia Marconi ${ }^{1}$

\begin{abstract}
RESUMEN
El republicanismo se ha convertido en una tradición importante en el debate en filosofía política y filosofía social, gracias a los trabajos de Philip Pettit y de Rainer Forst. Las ideas republicanas de Immanuel Kant pueden aportar a enriquecer el debate sobre el tema. El presente trabajo presenta la manera en la que es posible interpretar el imperativo categórico de Kant de modo que permita elaborar una concepción del republicanismo que tenga su punto de partida en la sociedad civil. En ese sentido, el texto explora la posibilidad de una interpretación práctica y consecuencialista del imperativo categórico que permita transmitir el republicanismo desde la sociedad civil al Estado.
\end{abstract}

\section{Palabras clave}

Immanuel Kant, imperativo categórico, republicanismo, consecuencialismo, sociedad civil

\begin{abstract}
Republicanism has become an important tradition in the debate on political and social philosophy, thanks to the work of Philip Pettit and Rainer Forst. The republican ideology of Immanuel Kant can contribute to enrich the debate on the subject. This paper presents the way in which it is possible to interpret Kant's categorical imperative so that it allows the conception of republicanism that has its starting point in the civil society. In this sense, the text explores the possibility of a practical and consequentialist interpretation of the categorical imperative, which makes it possible to transmit republicanism from the civil society to the State.
\end{abstract}

\section{Keywords}

Immanuel Kant, categorical imperative, republicanism, consequentialism, civil society

\section{INTRODUCCIÓN}

La interpretación clásica de la filosofía moral y política de Kant ha insistido en tres puntos que buscamos cuestionar en este texto. La primera es que la filosofía moral de Kant es formal y a priori, y que no es posible darle un sentido diferente. La segunda es que en Kant no hay una concepción de sociedad civil y que no es posible extraerla de sus textos por medio de una interpretación filosófica. Respecto de la primera cuestión, veremos cómo es posible ganar una concepción no puramente formalista, a través de la idea de que las personas son fines en sí y de la dinámica de intercambio de razones que toma en cuenta los elementos del contexto al interior de una estrategia constructivista; mientras que respecto de la segunda cuestión se verá cómo es posible pensar la necesidad de una sociedad civil a partir del mismo imperativo categórico, extrayendo de este una concepción relacional. El tercer punto

Magíster en Filosofía por la Pontificia Universidad Católica del Perú (PUCP). Miembro del Grupo de Investigación en Filosofía Social (GIFS) y de La Red Iberoamericana "Kant: Ética, Política y Sociedad" (RIKEPS). Profesor Ordinario del Departamento de Teología de la PUCP y profesor de la Carrera Profesional de Filosofía en la Universidad Antonio Ruiz de Montoya (UARM). 
que el presente trabajo busca es poner en cuestión derivada de las primeras, a saber, la interpretación clásica del republicanismo kantiano centrado en la estructura del Estado $^{2}$ y no partiendo de la sociedad civil.

En este sentido, el presente trabajo tiene como objetivo central abonar a un esclarecimiento de la idea kantiana de República mostrando la manera en la que Kant piensa que para la consolidación de un Estado republicano es necesario, primero, republicanizar las relaciones entre las personas en el seno de la sociedad civil. Desde la sociedad, civil surge una fuerza republicanizadora capaz de llegar hasta el Estado. Para esto, es necesario desarrollar la mirada de la moral kantiana como conteniendo un consecuencialismo con restricciones deontológicas basadas en una interpretación práctica de la contradicción que se encuentra en el corazón del imperativo categórico y que impulsa el desarrollo de relaciones republicanas tanto en la sociedad civil como en el Estado.

Kant era consciente de la importancia de la republicanización de las relaciones interpersonales al interior de la sociedad civil, si bien es cierto que no desarrolló una teoría sobre la misma, pero sí ofreció tanto una idea de "Reino de Fines" (Kant, 2012) como de "Comunidad Ética"(Kant, 2016), que pueden servir como punto de partida para desarrollar una idea de sociedad civil ${ }^{3}$. Habiendo bebido del escepticismo antidogmático de David
Hume y del pensamiento social y político antidespótico de Jean-Jaques Rousseau, el filósofo alemán tenía claridad respecto del peligro que entraña el que la sociedad civil sea conquistada por pensamientos dogmáticos ya que ello haría que las relaciones entre las personas estén basadas en la dominación. Es por ello que no basta con que el Estado sea republicano, para asegurar las condiciones de relaciones no despóticas en la sociedad y la misma preservación del Estado republicano. Resulta, más bien, que la consolidación de una sociedad civil republicana no solo garantiza mejor el fortalecimiento del Estado republicano, sino la construcción paulatina del mismo. El Estado republicano, fortalecido con una sociedad también republicana, permite dotar de la trasparencia adecuada al uso del poder de forma que se convierte en una herramienta adecuada para combatir la corrupción.

El presente estudio comenzará ubicando el republicanismo kantiano en el marco de las tradiciones republicanas más representativas (1). Seguidamente, se presentará el republicanismo kantiano partiendo de una interpretación del imperativo categórico que tiene una vena consecuencialista con restricciones deontológicas (2), para ver de qué manera, a partir de él, es posible establecer relaciones republicanas tanto en la sociedad civil como en el Estado (3). Finalmente, extraeremos las conclusiones centrales de lo presentado en las tres primeras secciones (4).

2 Esta interpretación es clásica, pero las versiones recientes de su defensa se encuentran en los textos de Reinhard Brandt (Brandt, 1997) y Peter Nissen (Niesen, 2001), entre otros.

3 También es posible encontrar bases para una teoría sobre la sociedad civil en los textos ¿Qué es Ilustración?, El conflicto entre las facultades, La doctrina de la virtud que está inserta en Metafísica de las costumbres y en otros textos. Además, es necesario señalar que la idea de Reino de fines se mantiene en un contexto moral, mientras que la de Comunidad ética brota de la reflexión sobre la eclesiología y tiene ribetes sociales más explícitos que permiten asumirlo como punto de partida para desarrollar una concepción kantiana de sociedad civil, desarrollo que se puede desplegar en diálogo y debate con los trabajos de Cohen y Arato (Cohen \& Arato, 2000) y con los trabajos de Habermas (Habermas, 2001, 2010). Dejaremos el desarrollo de estas ideas para trabajos posteriores.

Una cosa adicional, respecto al desarrollo de una idea de sociedad civil a partir de los recursos kantianos, es que esta arrojará una idea de sociedad civil, es decir, de una imagen de lo que debe ser la sociedad civil, en la cual se incluye necesariamente que esta sea republicana, de manera que el término "sociedad civil republicana" es una redundancia, puesto que no hay otra idea de sociedad civil que no sea la republicana, es decir, en la que las personas establezcan relaciones republicanas entre sí. El hecho de que, en las sociedades concretas, la sociedad no llegue a ser e impere entre las personas relaciones de dominación, ya es una cuestión diferente. En Idea de una historia universal en sentido cosmopolita (KANT, 2006) Kant establece la distinción pueblo civilizado y pueblo culto. Un pueblo es civilizado cuando cuenta con suficiente tecnología (agua potable, electricidad, internet, etc.) y suficiente diferenciación sistémica entre subsistemas sociales (subsistemas jurídico, político, religioso y económico). En cambio, un pueblo culto representa la realización social de la moral, de manera que la cultura, en este contexto, es la búsqueda de las razones que podemos compartir, la manera en la que la razón puede compartirse en Sociedad, y la voluntad individual se entiende como la puerta estrecha de las buenas razones en el mundo. 


\section{1.- El republicanismo kantiano en el marco de las tradiciones republicanas.}

El republicanismo es una tradición de pensamiento político que hunde sus raíces en la antigüedad clásica. Esta tradición toma una fuerzaimportanteenlaRepúblicaromanay, por medio de las ciudades italianas renacentistas, para a la modernidad, especialmente en el pensamiento político inglés y estadounidense, aunque también tuvo presencia en Francia, a través de Rousseau, y en Alemania, a través de Kant. El republicanismo no es una tradición homogénea, sino que tiene variantes. En lo que sigue, presentaremos las tres variantes más importantes a fin de poder ubicar con mayor precisión a Kant.

\section{1.- Las variantes del republicanismo}

El republicanismo es una tradición de pensamiento político que se remonta al pensamiento que floreció en el seno de la República romana 4 . Uno de los principales intelectuales de la República Romana ha sido Marco Tulio Cicerón, quien escribió su obra De re publica entre el año 55 a. C. y el 51 a. C (Cicerón, 2014). Sin embargo, hay quienes señalan, como lo hace John Pocock (Pocock, 2002) y sus seguidores como Charles Taylor (Taylor, 1985, 1997) y Alasdair MacIntyre (MacIntyre, 1987), que el pensamiento republicano hunde sus raíces en la Grecia clásica, especialmente con las obras de Aristóteles. Al mismo tiempo, hay quienes siguen ubicando sus orígenes en Roma, pero encuentran a Rousseau y Kant como autores decisivos de una de las tradiciones del republicanismo.

De esta manera, se presentan tres tradiciones dentro del debate contemporáneo respecto del republicanismo. La primera es aquella desarrollada por John Pocock, quien conecta el republicanismo con el pensamiento aristotélico. Los herederos de Pocock fueron los llamados "comunitaristas", especialmente Alasdair MacIntyre, Michael Sandel y Charles Taylor (aquellos que John Rawls denominó "humanistas cívicos" [Rawls, 2012]), quienes se centran en las virtudes cívicas y enfatizan el peso de la comunidad política y las libertades positivas en contra de las libertades negativas defendidas por el liberalismo.

La segunda es aquella que pasa por Quentin Skinner (Skinner, 1983, 1986b, 1986a) y Philip Pettit (Braithwaite \& Pettit, 2015; Pettit, 1999), y ancla el republicanismo clásico en el pensamiento político desarrollado en la República Romana. Esta segunda considera lo que hay que defender es la libertad individual, pero considera a las personas al interior de instituciones y del Estado, y que tales instituciones son las que permiten la defensa de la libertad. Por ello se trata de libertad como no dominación ${ }^{5}$. Finalmente, la tercera tradición se remite al republicanismo franco-prusiano, en la cual los referentes más importantes son Jean-Jacques Rousseau e Immanuel Kant. En la actualidad, se encuentra representada por autores contemporáneos como Rainer Forst (Forst, 2013; Pettit, 2013), Christine Korsgaard (Korsgaard, 2000, 2011) o Thomas Scanlon (Scanlon, 2003), y colocan en el centro la autonomía de la persona en tanto fin en sí. Esto no significa que estas tres sean las únicas tradiciones de pensamiento republicano que existen, sino que se trata de las más influyentes en el debate contemporáneo ${ }^{6}$.

\section{2.- Ubicación de Kant en el contexto del pensamiento republicano}

Kant se ha reivindicado reiteradas veces partidario del republicanismo. Prueba de ello es el hecho de que en el texto de La paz perpetua (Kant, 2018) tome partido por el Estado republicano y por una Federación de Estados republicanos. La tradición republicana en la que se inscribe es la que hemos denominado

4 La República Romana fue denominada también Res publica populi romani, Roma o Senatus populusque Romanus. Se inició en el año 509 a. C., al terminar la Monarquía romana tras la expulsión del último Rey, Lucio Tarquinio el Soberano. La República Romana llegó a su fin el año 27 a. C., al iniciarse el Imperio.

5 Pettit establece la distinción entre el republicanismo y el liberalismo señalando que la primera concepción está comprometida con la idea de libertad como no interferencia, mientras que la segunda lo está con la idea de libertad como no interferencia.

6 Hay quienes, como Pettit, establecen la distinción entre "republicanismo" y "neo-republicanismo" con el objetivo de distinguir los trabajos actuales sobre el tema de los trabajos clásicos. En nuestro caso, utilizaremos indistintamente el término "republicanismo". 
franco-prusiana. Tal como señalamos antes, la imprenta del pensamiento de Rousseau fue una de las razones que hizo que Kant se inclinara por el republicanismo. En este contexto, su republicanismo coloca como centro la autonomía de la persona y, como consecuencia de ello, se compromete con la idea de la libertad como no dominación. Ahora bien, tal como hemos señalado arriba, los estudios clásicos del republicanismo en Kant enfatizan la constitución del Estado republicano; en cambio, nosotros centraremos nuestros esfuerzos en ver de qué manera podría ser valioso para Kant pensar en un republicanismo que parta de la sociedad civil y vaya republicanizando al Estado desde abajo. Para poder presentar la manera en la que el republicanismo kantiano hunde sus raíces en la sociedad civil, es necesario que hagamos una interpretación filosófica del imperativo categórico. A ello nos dedicaremos en la segunda y en la tercera sección de este trabajo.

\section{2.- La interpretación consecuencialista del imperativo categórico.}

Resulta ser muy extendida la interpretación de la moral kantiana en términos deontológicos y anticonsecuencialistas. Las mismas ideas de Kant dan pie a dicha forma de ver su planteamiento moral, especialmente cuando otorga un lugar primordial al concepto de buena voluntad como base para la importancia de la motivación. Autores recientes como Allen Wood, Paul Dietrichson y J. Kemp han argumentado a favor de esta interpretación. Se trata de una visión que se ha consagrado como clásica. Sin embargo, existen otras interpretaciones de la moral del filósofo alemán. De hecho, David Cumminsky (Cumminsky, 1996) ha presentado una interpretación consecuencialista. Y H. J. Paton (Paton, 1971) ha presentado una interpretación teleológica de la moral kantiana. En este contexto, la posibilidad de pensar en una interpretación consecuencialista de la moral kantiana ya ha sido ensayada y se torna plausible. La filósofa estadounidense Christine Korsgaard (Korsgaard, 2011), ha presentado una perspectiva respecto del consecuencialismo en Kant, que es importante explorar para este trabajo. Ella presenta un mejor análisis y es capaz de hacer frente a un mayor número de problemas, además de llegar a conclusiones más razonables y moderadas, frente a otras interpretaciones ${ }^{7}$. La perspectiva de Korsgaard da pie a considerar que es posible entender la ética de Kant como un consecuencialismo que introduce restricciones deontológicas. Tales restricciones garantizan la autonomía de la que goza la razón al producir la ley moral y la autonomía de las que gozan las personas respecto de los poderes tutelares.

En esta sección, nos dedicaremos a la interpretación de la primera formulación del imperativo categórico desarrollada por la filósofa estadounidense. Para ello, comenzaremos con a) una presentación del consecuencialismo con restricciones deontológicas y del lugar que ocupan tanto Rawls como Kant en el desarrollo de la filosofía moral. En b) nos dedicaremos a analizar las relaciones entre el consecuencialismo y la primera formulación del imperativo categórico, bajo la idea de la interpretación de la contradicción práctica desarrollada por Korsgaard. Como dicha interpretación es más potente que las interpretaciones alternativas, veremos cómo ella puede superar los obstáculos más grandes que se presentan a las interpretaciones del imperativo categórico. En ese sentido, veremos la forma en la que puede hacer frente a los obstáculos que se derivan de la distinción c) entre acciones naturales $\mathrm{y}$ acciones convencionales y d) entre el uso teórico y el uso práctico de la razón. Finalmente, como nuestro estudio está estableciendo la conexión entre la interpretación de la contradicción práctica y el consecuencialismo con restricciones colaterales, examinaremos esa relación, para ver qué se puede sacar en claro al respecto tras la debida reflexión (e).

\footnotetext{
Cumminsky señala que, si uno toma la obra de Kant en conjunto, entonces podría darse cuenta de que su perspectiva es consecuencialista. Esta posición se basa en grandes generalizaciones que son difíciles de mantener. Frente a ello, Korsgaard indica que asumir una interpretación práctica del imperativo categórica permite hacer frente a muchos de los problemas que se le plantean.
} 


\section{1.- Consecuencialismo con restricciones deontológicas.}

En un artículo titulado "Las razones que podemos compartir: un ataque a la distinción entre valores relativos al agente $y$ valores impersonales" (Korsgaard, 2011, pp. 503562 ), Korsgaard señala que uno podría ver gran parte de la filosofía moral desarrollada durante el siglo XX como un intento de escapar del utilitarismo. Pero, además, sucede que todos esos intentos han fracasado una y otra vez, y que los filósofos han escapado de las manos de una doctrina utilitarista para terminar atrapados en las garras de otra. Ello se debe a que:

[Una] característica básica del punto de vista consecuencialista todavía permea y distorsiona nuestro pensamiento: la postura de que la moralidad trata de producir algo. A menudo, el resto de nosotros ha arrojado sus protestas como si meramente estuviera protestando en contra de la explicación utilitaria sobre qué es lo que debe producir el agente o cómo ha de hacerlo. Se ha caracterizado a las consideraciones deontológicas como 'restricciones colaterales' como si fueran esencialmente restricciones sobre la manera de cómo realizar los fines. Más aún: los filósofos han asumido persistentemente que el escenario fundamental de la moralidad es un escenario en el que uno hace algo a alguien o para alguien... [Pero] el escenario fundamental de la moralidad no es uno en el cual yo te hago algo a ti o tú me haces algo a mí, sino uno en el cual hacemos algo juntos. El tema central de la moralidad no es lo que podemos producir, sino cómo es que debemos relacionarnos unos con otros. Si sólo Rawls ha podido escapar al utilitarismo, es porque ha sido el único en haber entendido este punto por completo. Su escenario -la posición original- es un escenario en el que un grupo de gente debe realizar una decisión conjunta. Su labor es encontrar las razones que pueden compartir (Korsgaard, 2011, pp. 503-504).

En esta cita, se presentan varios puntos que suceden con el pensamiento moral durante el siglo XX: en primer lugar, la presencia del consecuencialismo en él, bajo la forma de que la tarea de la moral es producir algo (o hacer algo a o para alguien); en segundo lugar, el utilitarismo es una de las versiones más emblemáticas del consecuencialismo porque lo presenta en su forma pura, pero hay que tener en cuenta que existen otras formas de consecuencialismo ${ }^{8}$; en tercer lugar, las consideraciones deontológicas han sido caracterizadas como "restricciones colaterales" introducidas dentro de ese esquema; en cuarto lugar, Rawls ha sido el único que entendió este problema y por eso introdujo un giro fundamental en el pensamiento moral. El giro que él introdujo fue el de pasar de pensar la moral como orientada a fines -o a cosas que hacemos a o para alguien- a pensarla como algo que hacemos juntos -o como la tarea de buscar las razones que podemos compartir-. La posición original expresa claramente ese giro, debido a que los participantes en ella buscan ponerse de acuerdo respecto de los principios de la justicia. Finalmente, en quinto lugar, la posición original de Rawls no es interpretada aquí como un artificio racional, sino como una situación en que las personas intercambian razones de manera recíproca9. Rawls, recurriendo a una variante política original del constructivismo ${ }^{10}$,

\footnotetext{
8 Las diferentes variantes de consecuencialismo se diferencias por el tipo de restricciones que colocan a las consecuencias de las acciones para caracterizarlas como morales. Por ejemplo, el utilitarismo de Jeremy Bentham coloca como restricción el que las acciones terminen produciendo el mayor beneficio con el menor perjuicio, lo que se conoce como principio de utilidad. En el caso de del utilitarismo de John Stuart Mill añade al criterio de Bentham uno adicional, que es una consideración sobre la justicia. En el caso de Mill, el consecuencialismo se mantiene dentro de los márgenes del utilitarismo, porque conserva aún el principio de utilidad. En el caso de otros consecuencialismos, se coloca principios diferentes como límites para la consecuencia. Como veremos más abajo, en el caso de Kant, lo que se coloca como restricción al consecuencialismo es lo que podríamos denominar "principio de la autonomía de la persona", que se constituye como una restricción deontológica.

9 Ya en Teoría de la justicia Rawls utiliza el término "reciprocidad". Cf. Rawls, John (2004). Teoría de la justicia. México: FCE., p. 452, ss.

10 Rawls considera que está recurriendo a una variante del constructivismo moral kantiano, Sin embargo, estudiosos de la obra de Rawls, como Robert Paul Wolff, señalan que el punto principal de Rawls es que él pretende derivar principios sustantivos de condiciones meramente formales. Además, introduce un nuevo tipo de categoría en la filosofía política, a saber, una especie de "razón política" que permite elevar lo que en Kant se presenta en forma de razón práctica, en clave de la filosofía de la consciencia, a un nuevo espacio, a saber, la intersubjetividad de las razones. Estoy endeuda con Ronald Reyes respecto de esta aclaración.
} 
presenta a los participantes en la posición original como buscando juntos las mejores razones que puedan compartir para dar fundamento a los principios de la justicia para una sociedad bien ordenada. Esto que Rawls presenta en 1971 con su libro Teoría de la justicia, vuelve a aparecer en Liberalismo político en 1993 y en Una reformulación de la idea de razón pública en 1999. Tanto en 1993 como en 1999, Rawls introduce el modelo constructivista del intercambio de razones, como un procedimiento para desarrollar una razón pública que permita articular de mejor manera la idea de sociedad como sistema justo de cooperación.

En este punto, surgen las siguientes preguntas: aquello que Korsgaard señala respecto del lugar de Rawls en el pensamiento moral del siglo XX ¿̇se puede decir también en relación con la posición de Kant en el pensamiento moral del siglo XVIII, o Kant es también consecuencialista? En otras palabras, ¿el giro impreso por Rawls ha sido decisivo no solo para el pensamiento moral y político no solo en el siglo XX, sino también en el debate ético general en occidente? Si esto último es correcto, ello significaría que el pensamiento moral de Kant no escapa del consecuencialismo, sino que introduciría "restricciones colaterales" al mismo. En lo que sigue, veremos de qué manera la moral kantiana puede interpretarse como conteniendo una vena consecuencialista.

\section{2.- La primera formulación del imperativo categórico y la interpretación consecuencialista}

En un artículo titulado "La fórmula de la ley universal de Kant" (Korsgaard, 2011, pp. 173-220) Korsgaard argumenta a favor de una interpretación del imperativo categórico, a la que denomina "Interpretación Práctica". Ella examina la primera formulación del imperativo categórico y señala que allí el término "contradicción" ocupa un lugar central. Seguidamente identifica tres interpretaciones que pueden darse al término en cuestión en el texto de Kant; lo que ella denomina "Interpretación de la Contradicción Lógica" (ICL, en adelante), "Interpretación de la Contradicción Teleológica" (IPT, en adelante) e "Interpretación de la Contradicción Práctica"
(ICP, en adelante). Finalmente, termina defendiendo la ICP, porque resulta más coherente y resuelve mejor los problemas que tiene que enfrentar la primera formulación.

La primera formulación del imperativo categórico es presentada por Kant en el texto de la Fundamentación para la metafísica de las costumbres en los siguientes términos: "obra sólo según aquella máxima por la cual puedas querer que al mismo tiempo se convierta en una ley universal" (Kant, 2012/1785, 126 [A 52]). Y, más abajo, Kant señala que:

Como la universalidad de la ley por la cual tienen lugar los efectos constituye aquello que propiamente se llama naturaleza en su sentido más lato (según la forma), o sea, la existencia de las cosas en cuanto se ve determinada según leyes universales, entonces el imperativo universal del deber podría rezar también así: obra como si la máxima de tu acción pudiera convertirse por tu voluntad en una ley universal de la naturaleza. (Kant, 2012/1785, 126 [A 52]) (itálicas en el original).

De los pasajes citados se ve que querer universalizar una máxima inmoral termina produciendo una contradicción. Kant va a ser explícito al respecto cuando afirma que:

Este principio supone también por tanto una ley suprema: «Obra siempre según aquella máxima cuya universalidad como ley puedas querer a la vez»; ésta es la única condición bajo la que una voluntad nunca puede estar en contradicción consigo misma, y tal imperativo es categórico. (Kant, 2012/1785, 152 [A 81]) (negritas mías).

Korsgaard se plantea la cuestión de identificar en qué sentido se produce una contradicción al querer universalizar una máxima inmoral. Señala que existen tres interpretaciones diferentes de la contradicción a la que apela la primera formulación del imperativo categórico:

1) ICL: consiste en que hay una imposibilidad lógica en la universalización de la máxima, o 
en el sistema de la naturaleza en el que la máxima es una ley natural. De esta manera, si se universaliza la máxima, la acción o la pauta que la propone sería inconcebible. De lo que se trata aquí es de una contradicción en la concepción. Kant ha distinguido con claridad entre una contradicción en la concepción de una contradicción en la voluntad ${ }^{11}$ (O'Neill, 2013, 26-27).

2) ICT: consiste en que sería contradictorio querer tu máxima como una ley para un sistema de la naturaleza concebido teleológicamente. Esto es así porque o bien estarías actuando en contra de un propósito natural, o bien tu máxima no podría ser una ley teleológica.

3) ICP: consiste en que tu máxima se bloquearía a sí misma si se universalizara, debido a que frustraría su propio propósito. De esta manera, tu acción sería ineficaz para la consecución de su propósito si todo el mundo la usara o tratara de usarla para alcanzarlo. Se trata aquí de una contradicción en la voluntad.

Korsgaard completa su enumeración haciendo algunos comentarios adicionales:

En primer lugar, la fórmula de la ley universal que la primera formulación del imperativo categórico presenta es un test de la suficiencia de las razones de acción y elección que están incorporadas en nuestras máximas. Además, uno puede encontrar base textual para apoyar cualquiera de las tres interpretaciones. De hecho, Kant incorporó las tres interpretaciones en el texto de la Fundamentación para la metafísica de las costumbres sin hacer las distinciones del caso, debido, probablemente, a que él mismo no tenía claridad respecto de la diferencia entre las tres interpretaciones. En tercer término, por ello es necesario hacer una interpretación filosófica y no exegética, es decir, una interpretación que dé mayor coherencia al test de universalización y le permita enfrentar de mejor manera los problemas y cuestionamientos que se le presentan. En cuarto lugar, la ICP que Korsgaard defiende es superior a las otras dos interpretaciones porque enfrenta de mejor manera la distinción entre "acciones naturales" y "acciones convencionales" $y$, en ese sentido, es superior a la ICL, y porque se presenta como una interpretación conectada con el uso práctico de la razón y no con el uso teórico de la misma, siendo en ello superior a la ICL como a la ICT.

\section{3.- Acciones naturales y acciones convencionales}

Uno de los problemas serios que enfrenta la ICL es que no puede hacer frente a máximas como la que puede tener una madre que dice: "si doy a luz un bebé que pesa menos de tres kilos haré todo lo que esté en mi poder para matarlo"12. Esta interpretación deja pasar esta máxima sin problemas porque al universalizarla no se produce contradicción alguna, debido a que la pauta que indica no resulta ser inconcebible. La máxima de matar es de la misma naturaleza de la presentada aquí. También pasa la prueba de la ICL.

Este problema se produce debido a que la ICL no distingue entre acciones naturales $y$ acciones convencionales. Las acciones naturales no contienen reglas que se encuentren orientadas a algún propósito, de modo que no constituyen una práctica. En cambio, las acciones convencionales sí constituyen prácticas. Por práctica se entiende aquí: a) un conjunto de reglas, b) que son dadas por convención y c) que tiene como objetivo alcanzar un propósito (Rawls, 1999). De modo que si uno vulnera las reglas de

\footnotetext{
11 "Algunas acciones están constituidas de tal modo que su máxima no puede ser pensada sin contradicción como ley universal de la naturaleza y mucho menos que uno pueda querer que deba volverse tal. En otras no cabe detectar esa imposibilidad interna, pero sí resulta imposible querer que su máxima sea elevada a la universalidad de una ley natural, porque semejante voluntad entraría en contradicción consigo misma". (Kant, 2012, pp. 130-131/Ak IV, 424)

12 Esta máxima es presentada por Paul Dietrichson en "Kant's Criteria of Universality" y es tomada por Korsgaard en su texto.
} 
manera sistemática sucede que no se consigue el propósito o, si se consigue se termina por modificar a tal punto las reglas que la misma práctica se destruye. En esta segunda opción, puede suceder que se haya instaurado una nueva práctica con nuevas reglas para conseguir el mismo propósito, pero la práctica original ha sido completamente destruida por la universalización de máximas que atacaron de manera sistemática las reglas que esta implicaba.

Se podría reformular la máxima anterior de modo que incluya reglas que conduzcan a un propósito modificándola en los siguientes términos: "si doy a luz un bebé que pesa menos de tres kilos, haré todo lo que esté a mi alcance para matarlo, porque los niños que nacen con menos de tres kilos lloran mucho por la noche y no permiten que las madres descansen adecuadamente"13. En esta versión, se ha incluido un propósito y se han incluido reglas orientadas al mismo. Con estas modificaciones, sí se trata de una práctica, pero queda por examinar si se encuentra bien articulada y si se puede universalizar exitosamente.

Un ejemplo de acción convencional, y por lo tanto de práctica, es el pedir prestado sabiendo que no podré devolver el préstamo. Se trata de una acción convencional porque se inserta en una práctica que se ha generado a través de una convención, es decir, de un acuerdo entre las personas. La institución social del préstamo contiene reglas en vistas a un propósito, de tal manera que, si se violan las reglas de manera sistemática, se destruye o bloquea el propósito $y$, por lo tanto, una máxima inmoral destruye la práctica. Universalizar la máxima de pedir prestado sabiendo que no podré devolver el préstamo termina generando el efecto de que la misma solicitud del préstamo será tomada por los demás con sarcasmo. De esta manera, las acciones convencionales constituyen una práctica que incluye una interpretación de la contradicción que supera el problema contenido en la ICL. Esta nueva forma de interpretar la contradicción es la ICP.

\section{4.- Contradicción, uso teórico y uso práctico de la razón.}

Un problema adicional de la ICL comparte con la ICT. Ambas tienen una concepción de la contradicción, conectada con el uso teórico de la razón. Como es sabido, Kant establece la distinción entre el uso teórico y el uso práctico de la razón, y la moral se ubica en el contexto del segundo de estos usos (Kant, 2009). De esta manera, echar mano de una concepción teórica de la contradicción para el campo moral resulta problemático.

El uso práctico de la razón supone una concepción de la contradicción que se inserte en una práctica sostenida por la idea de libertad. Es decir, considera a las personas que se encuentran insertas en la práctica como autónomas y libres. La ICT se extrae de las prácticas y se conecta con una concepción teórica de los fines insertos en la naturaleza, de manera que no se considera a las personas ni como autónomas ni libres, sino como conectadas a los supuestos fines intrínsecos de la naturaleza. Al afirmar que uno no podría universalizar determinadas máximas porque bloquearían determinados fines naturales, está colocándose en el plano de las relaciones teóricas entre las reglas y los fines.

Mientras que la ICL hace abstracción de la relación de reglas que conducen a fines insertos en la naturaleza, la ICT las coloca en el centro. Pero un fin natural es muy diferente de un propósito inserto en una práctica convencional, ya que mientras que en el segundo escenario se ubican en el centro la autonomía y la libertad, en el primero de ellos estos son eliminados. Si bien la ICT y la ICP señalan que la contradicción se muestra en el resultado de la acción, que va en contra de un fin natural o de un propósito convencional, lo que distingue a ambas interpretaciones es que mientras la primera se enmarca en una concepción teórica de la contradicción, que bloquea determinados fines insertos en la naturaleza vistos desde el punto de vista teórico; la segunda, en cambio, se conecta con una concepción práctica de la contradicción,

\footnotetext{
13 Esta reformulación se encuentra en el texto de Korsgaard.
} 
que bloquea determinados propósitos insertos en prácticas convencionales articuladas por medio del uso práctico de la razón y que, por lo tanto, establecen relaciones entre personas libres y autónomas.

\section{5.-La“interpretacióndelacontradicción práctica" y el consecuencialismo con "restricciones colaterales"}

La interpretación de la ética kantiana como un consecuencialismo con "restricciones colaterales" tiene como base aquello que Christine Korsgaard denomina "interpretación de la contradicción práctica" que se encuentra operando al interior del imperativo categórico. Puede resultar controversial si la interpretación práctica a la que la autora estadounidense se refiere es una variante del consecuencialismo o es otra cosa. Hay tres posiciones al respecto: La primera sostiene que se trata de un consecuencialismo con restricciones deontológicas. La segunda, que nos encontramos en caso de una teoría moral deontológica pura, sin ninguna influencia consecuencialista. La tercera, finalmente, sostiene que nos encontramos ante una versión del constructivismo moral.

Para hacer frente a este desacuerdo, es necesario reparar en lo que significa el término "práctico", al interior de la "interpretación de la contradicción práctica". Parte de ese significado fue explicitado cuando presentamos el concepto de práctica desarrollado por Rawls. Para aclarar nuestro asunto, hemos de explicitar algunos aspectos adicionales de lo que dicho término significa. Lo primero que hay que señalar es que tiene menos que ver con el significado de práctico que surge del pragmatismo que con el concepto de práctico que brota del uso práctico de la razón. Para el pragmatismo, lo práctico es aquello que funciona en la experiencia, entendiendo la experiencia como configurada en un lenguaje intersubjetivo y estableciendo relaciones entre las personas y entre las personas y el mundo. Aquí, lo práctico tiene un sentido consecuencialista, puesto que se trata de tener éxito en nuestra acción en el mundo. En cambio, el concepto de práctico asociado al "uso práctico de la razón" está asociado a todo lo que se refiere a la libertad y coloca en el centro la relación interpersonal orientada al respeto incondicionado de la autonomía de las personas, en vez de referirse a promover ciertos estados en el mundo.

Esta interpretación de lo práctico basada en la idea del uso práctico de la razón se conecta mejor con una interpretación particular de la moral deontológica, que otorga un espacio a la relación interpersonal, a la vez que se encuentra entroncada con una concepción constructivista de la moral. La persona que quiere actuar de acuerdo con un principio moral lo hace en vistas de la motivación y no de las consecuencias. La persona quiere seguir una regla moral, más que querer promover un estado de cosas en el mundo. Su objetivo está centrado en la naturaleza de su motivación y no en las consecuencias de sus actos. El querer moral no es sino concebirse a sí mismo de cierta manera. La identidad práctica deriva en un conjunto de obligaciones. En Kant es quererse identificar como miembros del reino de fines. En la Crítica de la razón práctica, Kant aclara la cuestión del "querer" de una manera que permite distinguir con claridad el querer vinculado a objetos o a buscar promover determinados estados del mundo (que sería el querer consecuencialista, del querer moral, en términos del mandato que dice: actúa de acuerdo a una regla que sea parte de una legislación universal. En la formulación del imperativo categórico en la segunda crítica el término "querer" ha quedado suprimido para evitar cualquier ambigüedad respecto del consecuencialismo.

De esta manera, en Kant tenemos un deontologismo que dice: debes actuar conforme a un principio, pero que tu actuar sea efectivo en el mundo, no por el fin, sino por el deber mismo. Debes actuar de tal manera que generes efectos en el mundo, pero no centrando tu acción en los efectos, sino en una motivación correcta. De esta manera, queda claro que la misma exigencia moral significa que mi acción debe tener efectos en el mundo, pero no de la manera en la que lo pensaría un consecuencialista, sino porque estamos centrados en la motivación moral. Pero, actuar es siempre relacional. Al actuar, entramos en relación con otros, de tal manera que quien 
actúa motivado por el principio moral lo hace no solo buscando seguir la motivación, sino que la misma motivación incluye la exigencia de la efectividad de la acción en la relación interpersonal. En esa relación interpersonal, es central el considerarse a sí mismo y a los demás como fines en sí, dentro de un reino de fines. Esto hace que la acción que se deriva del motivo moral implica el respeto de la autonomía de todos los involucrados en la acción. En ese sentido, la interpretación del imperativo categórico más coherente es el que lo inserta en una práctica en la que lo relevante es el respeto incondicional de la autonomía de las personas. Pero, a su vez, dicha práctica le da a la moral kantiana una estructura constructivista.

El constructivismo es una estrategia de articulación de la moral que procura escapar de la necesidad de encontrar las exigencias morales en la naturaleza o de tener que inventarla (y caer en el relativismo). E constructivismo produce la ley gracias a reglas que son inherentes a la razón (Kant) o a las relaciones políticas (Rawls). La necesidad de recurrir al constructivismo surge de la constatación de que ya no podemos seguir operando con nuestras convicciones morales "naturales", que hemos venido asumiendo como dadas por sentado. Aquíse trata de salir de la ingenuidad natural de nuestras convicciones y de asumir la necesidad de construir las normas de acuerdo a reglas objetivas porque expresan la reflexividad inherente a la conciencia humana. La interpretación práctica del imperativo categórico que Korsgaard está apoyando captura en su concepción de práctica la exigencia de que asumamos un proceder constructivista de las normas.

De esta manera, la idea de que la moral kantiana es un consecuencialismo con "restricciones deontológicas" debe ser interpretada de la manera de la relacionalidad que la práctica implica. Dicho consecuencialismo remite necesariamente a la relación práctica, tal como la hemos precisado arriba. En ese sentido, es inconsistente con la idea de que la deontología de la moral kantiana exige efectividad en la práctica. Esto es así porque ambas cosas se pueden resolver en la estrategia constructivista de la misma moral kantiana.

\section{3.- La ICP, consecuencialismo y sociedad civil}

La ICP permite hacer frente a los problemas que las otras dos interpretaciones tienen, de modo que se presenta como el mejor camino que podemos tomar para leer la primera formulación del imperativo categórico. Esta interpretación nos conduce directamente a la conexión entre la moral kantiana y el consecuencialismo. Esta conexión se da al entender que la contradicción que se presenta al intentar universalizar máximas inmorales trae como consecuencia el bloqueo del propósito buscado en la práctica en cuestión. Esto hace que la razón por la cual no es posible universalizar la máxima en cuestión es que genera una consecuencia no deseada, a saber, la de bloquear el propósito inherente a la práctica. Además, puesto que la práctica es una convención que se establece para la relación entre las personas y esta relación debe asumir la dignidad de estas, $y$, por lo tanto, concebirlas como libres; la misma idea de práctica coloca restricciones al consecuencialismo, restricciones que son de carácter deontológico. Así, lo que tenemos en la moral kantiana es un consecuencialismo con restricciones deontológicas. Estas restricciones deontológicas están puestas por la exigencia del trato entre las personas como igualmente dignas y libres, exigencias que brotan de las prácticas cuyos propósitos la universalización de la máxima no debería bloquear para ser considerada una exigencia moral.

El imperativo categórico genera un efecto en el mundo, a saber, establecer relaciones recíprocas entre personas consideradas libres e iguales. La universalización de máximas inmorales, en cambio, quiebra las relaciones recíprocas que articulan la sociedad. Una sociedad civil fortalecida se encuentra cimentada en esas relaciones recíprocas. El imperativo categórico tiene una fuerza articuladora para la sociedad civil en el sentido de que instaura relaciones de reciprocidad positiva y carentes de dominación. Pero esta fuerza no se detiene allí, sino que plantea exigencias para que la relación entre el Estado y la sociedad sea republicana y que el mismo Estado se republicanice en su interior. En esta sección, veremos la manera 
en la que se puede establecer una relación entre las tres formulaciones del imperativo, siguiendo el hilo de la ICP y la forma en la que esta permite establecer una relación entre la sociedad civil y el Estado republicanos. Es por ello que en lo que sigue comenzaremos a) presentando la relación entre la interpretación consecuencialista de la moral kantiana con la segunda formulación (referente a la humanidad) y la tercera formulación (referente al reino de los fines); para estudiar más a profundidad la relación con b) la idea de humanidad y c) la idea de reino de los fines. Esta última idea nos conduce a d) una relación estrecha con la idea de sociedad civil que al ser una idea republicana se instaura sobre la base de la exigencia de no dominación que se encuentra presente e) lo que Rainer Forst denomina principios de justificación.

\section{1.- La interpretación consecuencialista, la humanidad y el Reino de los fines.}

La primera formulación del imperativo categórico se encuentra internamente conectada con las otras dos formulaciones que se presentan en el texto de la Fundamentación para una metafísica de las costumbres. Mientras que la primera formulación se centra en la fórmula de la ley universal, la segunda se centra en el valor de la humanidad y la tercera desemboca en la comunidad moral que Kant denomina Reino de Fines. La ICP que se encuentra en la primera formulación permite establecer la relación con la segunda y la tercera formulación. Como señala Korsgaard (Korsgaard, 2011, p. 221), las tres formulaciones del imperativo categórico que se presentan en el texto de la Fundamentación tienen un hilo conductor: la primera formulación apunta a la universalidad, es decir, con la forma que tiene la ley moral; la segunda formulación nos da materia de la ley, es decir, a la naturaleza racional de la humanidad a la que la ley se aplica, materia entendida como un fin en sí misma. La tercera formulación nos ofrece una determinación completa de las máximas y de la totalidad de fines en la idea de legislación autónoma en un Reino de los Fines. El recorrido completo por las tres formulaciones termina desembocando en el tercer capítulo de la Fundamentación, donde se presenta es esbozo de una crítica de la razón práctica a través de la presentación de la distinción entre fenómeno y noúmeno.

La idea de práctica inherente a la primera formulación nos conduce a encontrar en el valor incondicional de la humanidad una restricción al consecuencialismo (núcleo de la segunda formulación), a la par de establecer una conexión sistemática entre las personas entendidas como fines en sí al interior de una comunidad de carácter moral, que Kant denomina Reino de fines (contenido de la tercera formulación del imperativo categórico). Así, cada formulación apunta a la constitución de una sociedad civil en la que las personas establecen relaciones republicanas y que de esta brota la fuerza para dotar al Estado de una forma republicana.

\section{2.- La humanidad}

La segunda formulación del imperativo categórico explicita las restricciones que las prácticas sociales deben respetar. Esta explicita que no se debe tratar jamás a una persona como un simple medio, sino como un fin en sí. La exigencia de respetar incondicionalmente a cada persona tiene su fuente en el hecho de que ellas son seres racionales. Para Kant, los seres racionales deben ser considerados como fines en sí debido a que ellos son la fuente del valor. Mientras que los demás seres en el mundo se encuentran vinculados a reglas causales que los tornan condicionales, los seres humanos, en tanto racionales, son incondicionales. Ellos no se encuentran determinados por las relaciones causales operantes en el mundo natural, sino que, aunque se encuentren condicionados por dichas leyes, son capaces de determinarse a sí mismos a la acción; ellos son capaces de actuar por razones.

Esta idea ya se encuentra presente al inicio del texto de la Fundamentación cuando se señala que lo único que cuenta con valor moral es la buena voluntad (Kant, 2002, pp. 63/Ak IV, 393). Una voluntad dotada de razón es lo único bueno debido a que ella es la fuente de la normatividad y, por ende, de valor. Esto hace que las personas, por el hecho de ser seres racionales, sean el fin incondicionado 
del orden moral y meros medios del mundo natural. A través de la afirmación de la autonomía de la persona, en tanto fuente de la ley moral, Kant logra dar un giro crucial al pensamiento moral. Mientras que antes, la fuente del valor se encontraba fuera y la persona era siempre heterónoma, después de Kant sucede que la fuente del valor es el mismo ser racional (Korsgaard, 2011, p. 17). De este modo, se coloca la dignidad de la razón en el centro del mundo moral. Es en este sentido que en las prácticas dentro de la sociedad civil las personas deben tratarse mutuamente como fines en sí. La exigencia de no instrumentalizar a nadie se hace presente con toda su fuerza.

\section{3.- El Reino de fines}

Con la tercera formulación del imperativo categórico, la reflexión moral desemboca en la idea del Reino de fines, la cual se presenta como la idea de la sociedad civil. Este Reino se constituye como una "república moral" de personas que se tratan mutuamente de acuerdo con pautas morales, es decir, se tratan con fines en sí y no como medios. Se representa a las personas a la vez como legisladores y como súbditos, resultando una articulación social en la que los sujetos se dan leyes morales mutuamente por medio del uso autónomo de su razón. Cualquier persona en la posición de súbdito puede examinar la validez de las leyes morales de dicho reino.

El Reino de fines es una "república moral" y no una "república política" porque las leyes que relacionan a las personas son morales y no jurídicas. Las leyes morales son leyes de la libertad interior y señalan en qué sentido debemos determinar nuestra voluntad en las relaciones intersubjetivas. Las leyes jurídicas son leyes de la libertad exterior y demarcan el campo de acción de las personas que no puede ser vulnerado por otros dentro de la interacción social en el contexto del Estado o en el del concierto de Estados en el plano internacional. De esta manera, mientras que la libertad interior apunta directamente a la virtud, la libertad exterior se centra en la justicia. Es por ello que las leyes de la libertad exterior son jurídicas.
Kant señala que la tercera formulación del imperativo categórico sintetiza, en la idea del Reino de fines, las dos formulaciones anteriores. En este sentido señala que:

El fundamento de toda legislación práctica se halla objetivamente en la regla y la forma de la universalidad que la capacita para ser una ley (acaso una ley de la naturaleza), pero se halla subjetivamente en el fin, según el primer principio. Pero el sujeto de todos los fines es cualquier ser racional como fin en sí mismo, con arreglo al segundo principio; de aquí se sigue ahora el tercer principio práctico de la voluntad, como suprema condición de la concordancia de la voluntad con la razón práctica universal, la idea de la voluntad de cualquier ser racional como una voluntad que legisla universalmente. (Kant, 2002, p. 119/Ak IV, 431).

De esta manera, la tercera formulación sintetiza y potencia las dos primeras en dicha "idea de la voluntad de todo ser racional como una voluntad universalmente legisladora". Con ello se consolida la articulación social regida por leyes morales. El imperativo categórico, en sus diferentes aspectos, muestra su potencial articulador entre las personas al interior de la sociedad civil. De esta forma, la ICP ofrece una mirada consecuencialista que parte de la primera a la tercera formulación del imperativo categórico y que permite arribar a la idea republicana de sociedad civil.

\section{4.- Del Reino de fines a la sociedad civil republicana}

La ICP presentada por Korsgaard permite ver cómo la primera formulación del imperativo categórico contiene los gérmenes de la segunda y la tercera formulación. La idea de práctica que se encuentra en el corazón de esta interpretación implica que esta se desarrolla en el seno de las relaciones entre personas y que en ellas se exige que estas se traten como fines en sí. Quien intente proceder de acuerdo con una máxima inmoral, logra tener éxito solo tratando a las personas como medios para sus propios fines. La misma idea 
de práctica en la que se está introduciendo la primera formulación del imperativo categórico incorpora también la exigencia de tratar al otro como un fin en sí.

Esto implica el establecimiento de relaciones entre las personas como si se encontrasen en un Reino de fines, en el cual cada persona es considerada como colegislador moral y súbdito al mismo tiempo, de modo que las relaciones que se establecen entre ellos es la de personas libres e iguales. Este no es otra cosa que una representación de la sociedad civil. Las relaciones que se establecen en él son las que se espera tengan entre sí los miembros de la sociedad civil, a saber, de mutuo respeto entre personas libres e iguales. Las personas se encuentran insertas en relaciones morales que son relaciones de reciprocidad positiva (Sahlins, 2010, pp. 211-213).Tratarse mutuamente como fines en sí en el seno de la sociedad civil es tener relaciones republicanas. El republicanismo es la concepción de la democracia que enarbola la bandera de la libertad como no dominación (Pettit, 1999, pp. 78-89). El tratar al otro como un simple medio y no como un fin es someterlo a condiciones de reciprocidad negativa (Sahlins, 2010, pp. 213214) lo cual implica mantenerlo en relaciones de dominación.

A partir de la propia sociedad civil surge la exigencia de que la relación entre ella y el Estado sea del tipo republicano. Así, el Estado no debe imponer dominación sobre la sociedad civil (a excepción de la dominación legítima que proviene del derecho que contenga en sí la idea de libertad). Además, el republicanismo debe presentarse en la relación entre los mismos poderes del Estado, debe prevalecer la exigencia de no dominación, de modo que entre el poder ejecutivo, legislativo y judicial se encuentre una adecuada separación y respeto. Esta exigencia de separación de poderes del Estado brota del mismo imperativo categórico. Por eso, del imperativo categórico deriva la exigencia de instaurar el principio de separación de poderes en el Estado.

\section{5.- El republicanismo y el derecho a la justificación}

Uno de los elementos centrales de la teoría republicana contemporánea de raigambre kantiana es el principio que Rainer Forst denomina el derecho moral básico a la justificación. "Este derecho expresa la exigencia de que no existan relaciones políticas o sociales de gobernanza que no puedan justificarse adecuadamente ante los afectados por ellas" (Forst, 2017, p. 2) (la traducción es mía). Este principio viene a colación a partir de dos hechos fundamentales. El primero es que, más allá de todas las definiciones que desde la tradición de la filosofía se ha dado al ser humano (animal racional, animal social, animal político o animal dotado de lenguaje, entre otras), lo que queda en el trasfondo común es que los seres humanos somos "seres justificatorios" (Forst, 2012 , p. 1). El segundo hecho es que todas las personas nos encontramos siempre dentro de relaciones sociales y políticas que implican ciertas normas y exigencias. Este conjunto de normas constituye un "orden normativo" (Forst, 2012, p. 46), orden en el que las personas se encuentran insertas. Este se presenta tanto en las instituciones de relaciones más cercanas (como la familia), como las que se encuentran en la sociedad civil (como los clubes, las iglesias y las universidades) y a nivel político (como es el caso de las leyes jurídicas). Estos órdenes normativos pueden convertirse en "órdenes justificatorios" cuando las personas que se encuentran insertas en ellos cuentan con el derecho básico a la justificación. Este derecho se constituye en un principio básico, tanto moral como político, que debe servir para articular las exigencias morales, jurídicas y políticas de la sociedad y de la comunidad política.

El derecho a la justificación consiste en la posibilidad que tienen las personas a que se le justifiquen, por medio de razones, las normas a las que se encuentran ligadas. Una razón es un elemento cognitivo que es susceptible a intercambio, crítica y fundamentación. Se trata de un interés comunicable $e^{14}$. Thomas Scanlon señala que una razón es un "elemento primario". De esta manera, el filósofo estadounidense

14 Estoy en deuda con Ciro Alegría Varona respecto de esta definición de lo que es una razón. 
señala que "[c]onsideraré la idea de una razón como primitiva. Me parece que cualquier intento de explicar qué es ser una razón para algo nos obliga a retroceder a la misma idea: una razón para algo es una consideración que cuenta a su favor" (Scanlon, 2003, p. 33). A diferencia de una explicación (que se ubica en el terreno de las descripciones y de las relaciones causales operantes en el mundo), una razón es determinante para la acción. Una razón es siempre una razón para actuar o para creer (creer es una forma de actuar). Mientras que las explicaciones solamente tienen contenido (a saber, la descripción del estado de cosas en el mundo del que da cuenta), una razón tiene no solo un contenido, sino también un carácter (son morales o no; es correcta o incorrecta).

El derecho a la justificación de una persona es respetado cuando la institución en cuestión se encuentra dispuesta en dar razones respecto de las normas que la afectan. De lo contrario, se estaría ejerciendo dominación sobre ella (WartenbergThomas, 1990). El argumento basado en el derecho a la justificación es, de acuerdo con Forst, "el mejor modo posible de reconstruir el imperativo categórico kantiano de respetar a otras personas como fines en sí mismas" (Forst, 2012, p. 2) (la traducción es mía). Es decir, el derecho a la justificación coloca a las personas como sujetos autónomos que no son tratados como objetos pasivos a los que simplemente se les aplican las normas del orden normativo, sino que son considerados como seres activos capaces de exigir razones respecto de las exigencias que se encuentran en el orden normativo. Al considerar a las personas como seres activos, se los considera como racionales y como fines en sí mismos. Que una persona sea un fin en sí supone tres cosas a la vez. La primera es que no puede ser tratada como un objeto, al que se le puede manipular. La segunda es que la persona es la única que tiene el derecho de darle fines a su propia vida, y no está permitido que ninguna otra persona o institución (basado en un supuesto conocimiento sobre fines y valores) imponga fines a su vida. Finalmente, la tercera es que una persona considerada como un fin en sí mismo es un ser justificatorio, es decir, debe tener el derecho básico a la justificación.
El principio de justificación se apoya en la idea de que las personas se encuentran en la dinámica de dar y recibir razones. Las razones que se intercambian en dicha práctica son generales y recíprocas (o mutuas). El que el intercambio de razones tenga que ser general y recíproco se debe a que el principio moral de la justificación incorpora los criterios de generalidad y reciprocidad. Forst señala que:

Reciprocidad significa que nadie puede rechazar las demandas particulares de los demás (reciprocidad de contenido), y que tampoco nadie puede simplemente asumir que los demás tienen los mismos valores $e$ intereses que uno o recurrir a "valores superiores" (reciprocidad de las razones). Generalidad significa que las razones de las normas básicas generalmente válidas deben ser compartibles por todos los afectados. (Forst, 2012, p. 5)

El que las razones sean generales significa que pueden ser válidas para todos los implicados en la relación concreta de justificación. El que las razones sean recíprocas significa que las personas implicadas en la relación de justificación se consideran unas a otras con el derecho a tener razones de parcialidad. Quien ha trabajado de manera particular el lugar que tiene la imparcialidad y la parcialidad en la ética ha sido Thomas Nagel. Para Nagel, la cuestión ética no puede ser absorbida por completo por la imparcialidad y la igualdad, sino que la parcialidad tiene un lugar importante en la experiencia ética cotidiana, y encuentra en Kant la base para esta dualidad del yo entre lo impersonal y lo personal, en el hecho de que la vida de cada uno es igualmente importante $y$ en que cada uno tiene que orientar su propia vida (Nagel, 1996, p. 50). Con estas herramientas, Nagel presenta lo personal en estos términos:

El material primario, a partir del cual comienza la ética -los objetivos personales, los intereses y los deseos de los individuos que el punto de vista impersonal incorpora o presuponeforma parte, completamente, del punto de vista de cada uno de los individuos. 
Con frecuencia, la perspectiva personal también presupone fuertes lealtades personales hacia particulares comunidades de interés o de convicción o por identificación emocional, más amplias que las definidas por amistad o familiares, pero así y todo sin llegar a ser universales. (Nagel, 1996, p. 20)

Las razones de parcialidad son aquellas que una persona tiene debido a las relaciones que establece con otros por su situación en el mundo social. Por ejemplo, un juez tiene razones de parcialidad para no juzgar a un familiar, al igual que un médico las tiene para no operar a su hijo. Este tipo de razones son completamente válidas y dependen de las relaciones específicas en las que los agentes se encuentren. De esta manera, se trata de un principio moral básico al que se llega a través de un procedimiento constructivista y, también, reconstructivista. Es constructivista porque se articula sobre la base de la estructura básica de la justificación. De la misma estructura de la justificación brotan las exigencias morales, de manera que no se requiere recurrir a ningún elemento externo, sea empírico o metafísico. Además, esa misma estructura exige el intercambio de razones para poder evaluar cuáles se encuentran mejor fundamentadas.

Es reconstructivista porque uno lo puede ver surgir en los conflictos históricos reales (como es el caso de los conflictos en torno a la tolerancia). En este último punto, el principio de justificación no nos remite a un simple consenso, sino a un intercambio de razones en situaciones de conflicto $y$ desacuerdo. En contexto de conflictos es posible arribar a buen puerto debido a que es posible reconocer cuándo una razón es más fuerte que otra. Es por esto que el derecho a la justificación no solo concede un derecho a voz respecto de las materias en cuestión, sino también un derecho a veto contra normas básicas, arreglos y estructuras que no puedan justificarse reciprocidad $y$ generalmente ante cualquier afectado (Forst,
2012 , p. 6). Este aspecto reconstructivo abre las puertas a que la historia se pueda ubicar en el centro del pensamiento moral y político, no en el sentido de recuperar alguna fuente moral perdida en el pasado (como lo sugiere la hermenéutica culturalista), sino para ver de qué manera los conflictos históricos han ayudado a poner en claro, a través de sus desacuerdos, los principios normativos fundamentales tanto morales como políticos. De esta manera, la ética del igual respeto es entendida como construida en procesos históricos de conflicto.

Este intercambio de razones es siempre contextual, se da siempre en contextos específicos de justificación. De esta manera, aunque se trata de una posición basada en Kant, se aparta de la moral apriorista. Además, dicho intercambio no es un simple debate en la esfera pública (como puede provenir de posiciones basadas en Arendt y Aristóteles), sino que se trata de un intercambio de razones de carácter cognitivista y constructivista. Es cognitivista ${ }^{15}$, porque se centra en cogniciones, a saber, en razones. En ese sentido, no toma en cuenta elementos metafísicos, como las condiciones del alma humana o las bases universales para el desarrollo humano o el despliegue de las capacidades básicas. Es constructivista porque a través del intercambio de razones se va articulando las exigencias morales $y$ políticas. Pero también es de bases kantianas. Se centra en la autonomía del sujeto y considera a la persona como un ser racional que se encuentra inserto en el mundo social. En cuanto racional, tiene la posibilidad de activar sus capacidades reflexivas y tomar distancia de su contexto. En tanto inserto en el mundo social, se encuentra con otros sujetos en un intercambio de razones. De esta manera, se compromete con la autonomía desde la perspectiva kantiana de la razón práctica (Forst, 2012/2007, 34). El derecho a la justificación se puede ubicar tanto en el plano de la sociedad civil, como en el plano del Estado. En este sentido, es de carácter moral y político. Se puede institucionalizar

15 Es cognitivista, pero a diferencia de Habermas, no es hipercognitivista. Este enfoque incluye el intercambio entre personas, con todos los lazos afectivos que ello implica, tal como lo presenta Rousseau en sus textos. 
tanto en la sociedad civil como en el Estado. La finalidad de este derecho es evitar la dominación y permite tener una concepción republicada de raíz kantiana, definiendo el republicanismo como justicia, como no dominación (Forst, 2013). De esta manera, permite construir relaciones republicanas en ambos campos.

\section{4.- Conclusiones}

A contrapelo de la mirada de la moral kantiana, como formalista y a priori, lo que hemos visto es que, si uno inserta su filosofía moral, social y política en el marco de la tradición republicana, esta concepción clásica puede ser cuestionada. De otro lado, hay interpretación del republicanismo kantiano que tiene su centro en la configuración del Estado republicado, a contrapelo de la cual hemos afirmado la idea según la cual es posible extraer de la filosofía de Kant la exigencia de comenzar por republicanizar a la sociedad civil, para después poder republicanizar el Estado.

Ambos elementos se encuentran interconectados, desde que la republicanización de la sociedad civil parte justamente de la dinámica que se opera en el corazón de la interpretación del imperativo categórico. Así, en cambio de pensarlo, desde su primera formulación, como no relacional, se ha podido dotarlo de una interpretación en la que las relaciones sociales se encuentran en el centro, gracias a la ICP que Korsgaard nos ha ofrecido. Esta interpretación relacional hace que desde la primera formulación del imperativo categórico se genere una dinámica relacional, gracias a cierta deriva consecuencialista inserta en él. Esta dinámica conduce a la centralidad de la humanidad en el entorno de un reino de fines. De esta manera, esta mirada de la ética y la filosofía social de Kant alcanza su desarrollo actual en el principio de justificación desarrollado por Forst. El principio de justificación se presenta como una versión del mismo imperativo categórico que permite establecer relaciones republicanas tanto en la sociedad civil como en el Estado, gracias a una adecuada institucionalización de este. De esta manera, con el apoyo de las ideas de Kant y de los kantianos contemporáneos, es posible iluminar en concepto de republicanismo que, de un tiempo a esta parte, ha tenido presencia en los debates tanto en la filosofía social como en la filosofía política. 


\section{REFERENCIAS}

Braithwaite, J. y Pettit, P. (2015). No solo un mercado. Por una justicia penal que vaya más allá del castigo. Buenos Aires: Siglo XXI Editora Iberoamericana.

Brandt, R. (1997). "Antwort auf Bernd Ludwig: Will die Natur unwiderstehlich die Republik." Kant-Studien, 88, 218-228.

Cicerón, M. T. (2014). La república. Madrid: Alianza Editorial.

Cohen, J. y Arato, A. (2000). Sociedad civil y teoría política. México: Fondo de Cultura Económica.

Cumminsky, D. (1996). Kantian consequentialism. New York: Oxford University Press.

Forst, R. (2012). The right to justification. Elemens of a constructivist theory of justice. New York: Columbia University Press (Original publicado en el 2007).

Forst, R. (2013). A Kantian republican conception of justice. In A. Niederberger and P. Schink (Eds.), Republican democracy. Liberty, law and politics (pp. 154-168.). Edinburgh: Edinburgh University Press.

Forst, R. (2017). Normativity and power. Analizing social orders of justification. Oxford: Oxford University Press.

Habermas, J. (2001). Facticidad y validez. Sobre el derecho y el estado democrático de derecho en términos de teoría del discurso. Madrid: Trotta.

Habermas, J. (2010). Teoría de la acción comunicativa. Madrid: Trotta.

Kant, I. (2002). Fundamentación para una metafísica de las costumbres (R. Aramayo, Ed.) (Original publicado en 1785).

Kant, I. (2006). Ideas para una Historia Universal en clave cosmopolita. En Ideas para una Historia Universal en clave cosmopolita y otros escritos sobre Filosofía de la Historia. México: UNAM.

Kant, I. (2009). Crítica de la razón pura. México: UNAM/FCE (Original publicado en 1789, primera edición, y en 1787 segunda edición).

Kant, I. (2012). Fundamentación de la metafísica de las costumbres. R. Aramayo (Ed.), Madrid: Alianza editorial (2.a ed., Vol. 1785) (Original publicado en 1785).

Kant, I. (2016). La religión dentro de los límites de la mera razón (Original publicado en 1793).

Kant, I. (2018). Hacia la paz perpetua: un proyecto filosófico (R. Aramayo, ed.). Madrid: Ediciones Alameda.

Korsgaard, C. (2000). Las fuentes de la normatividad. México: UNAM (Original publicado en 1996).

Korsgaard, C. (2011). La creación del reino de los fines (Original publicado en 1996).

MacIntyre, A. (1987). Tras la virtud. Barcelona: Crítica. 
Nagel, T. (1996). Igualdad y parcialidad. Bases éticas de la teoría política. Barcelona: Paidós (Originalmente publicado en 1991).

Niesen, P. (2001). "Volk-von-Teufeln-Republikanismus. Zur Frage nach den moralischen Ressourcen der liberalen Demokratie." In L. Wingert \& K. Günther (Eds.), Die Öffentlichkeit der Vernunft und die Vernunft der Öffentlichkeit (pp. 568-604). Frankfurt am Main: Suhrkamp.

Paton, H. J. (1971). The categorical imperative. A study in Kant's moral philosophy. Pennsylvania: Pennsylvania University Press.

Pettit, P. (1999). Republicanismo: una teoría sobre la libertad y el gobierno. Barcelona: Paidós (Original publicado en 1997).

Pettit, P. (2013). Two republican traditions. In A. Niederberger, and P. Schink (Ed.), Republican democracy. Liberty, law and politics (pp. 169-204). Edinburgh: Edinburgh University Press.

Pocock, J. (2002). El momento maquiavélico: el pensamiento político florentino y la tradición republicana atlántica. Madrid: Tecnos.

Rawls, J. (1999). Two conceps of rules. In S. Freeman (Ed.), Collected Papers (pp. 20-46). Mssachusetts: Harvard University Press.

Rawls, J. (2012). La justicia como equidad. Una reformulación. Barcelona: Paidós.

Sahlins, M. (2010). Economía de la edad de piedra. Madrid: Akal.

Scanlon, T. (2003). Lo que nos debemos unos a otros: ¿qué significa ser moral? (Original publicado en 1998).

Skinner, Q. (1983). Machiavelli on the maintenance of liberty. Politics, 18, 3-15.

Skinner, Q. (1986a). The Paradoxes of political liberty. Tanner Lectures on Human Values, VII, 225-250.

Skinner, Q. (1986b). The republican ideal of political liberty. In G. Bock, Q. Skinner and M. Viroli (Eds.), Machiavelli and republicanism (pp. 293-309). Cambridge: Cambridge University Press.

Taylor, C. (1985). Philosophy and the human sciences. Cambridge: Cambridge University Press.

Taylor, C. (1997). Argumentos filosóficos: ensayos sobre el conocimiento, el lenguaje y la modernidad. Barcelona: Paidós.

Wartenberg, T. (1990). The forms of power: From domination to transformation. Philadelphia: Temple University Press.

Fecha de recepción: 12-06-19.

Fecha de aceptación: 30-06-19. 